\title{
THE FAILURE OF THE DANIELS CASE: BLINDLY ENTRENCHING A COLONIAL LEGACY
}

\author{
LARRY CHARTRAND*
}

\section{INTRODUCTION}

A 12-year court battle over whether Métis and non-status Indians are included within the meaning of "Indians" as defined in section 91(24) of the Constitution Act, 1867 ended this year. ${ }^{1}$ The Congress of Aboriginal Peoples and three individual plaintiffs brought an action for a declaration that Métis and non-status Indians (those excluded from the Indian Act ${ }^{2}$ ) fell within the scope of section 91(24). As a result of the decision, the federal government has exclusive jurisdiction to legislate not only over Indians (those with status under the Indian Act) but also Métis and non-status Indians. ${ }^{3}$ The Federal Court (Trial Division) held that Métis and non-status Indians fell within the scope of the term "Indians" in section 91(24). Justice Phelan held that such an inclusive definition is consistent with the purpose and intent of the provision based on the evidence as applied through the lens of contemporary Constitutional interpretation principles. ${ }^{4}$

There are many emerging issues that Daniels raises, such as jurisdictional immunity from provincial laws, the impact on the existing Métis settlements legislation in Alberta, the problems with the limited expert historical evidence, and the theoretical problems with identity classification based on ethnic, as opposed to political, lines. The case also raises some broader fundamental issues concerning the nature of Canada's legal relationship with Indigenous nations. This case comment concentrates on the scope and nature of section 91(24) and how it is unlike any other head of power in the Constitution. This discussion is limited to the problem of understanding the true nature of section 91(24) in a Canada committed to a decolonizing relationship with the Indigenous peoples and the failure of the parties and the court to appreciate a third equity-based alternative on how to define the nature and scope of section 91(24).

For many, the Daniels case is seen as a victory. The decision ends a long and sometimes bitter dispute over which level of government, the provinces or the federal government, has primary jurisdiction to legislate with respect to Métis and non-status Indians. This jurisdictional dispute has often resulted in Métis and non-status Indian communities and individuals falling between the cracks of government policy or programs as neither level of

Associate Professor, Faculty of Law, Common Law Section, University of Ottawa.

(UK), 30 \& 31 Vict, c 3, reprinted in RSC 1985, App II, No 5; Daniels v Canada (Minister of Indian Affairs and Northern Development), 2013 FC 6, 357 DLR (4th) 47 [Daniels]. The decision, however, has been appealed to the Federal Court of Appeal and will most likely be appealed to the Supreme Court of Canada.

RSC 1985, c I-5.

In a much earlier decision, the Supreme Court of Canada, in Re Eskimo, [1939] SCR 104, held that Inuit are included within the definition of section 91(24). They are not included, however, within the definition of Indian as defined in the Indian Act and thus are excluded from the benefits that flow from having status. This exclusion is one of the motivations behind the Daniels litigation. Daniels, supra note 1 at paras 534-44. 
government was willing to accede to such responsibilities. ${ }^{5}$ Although the decision resolves this debate (subject to appeal) and adds clarity to constitutional responsibility, this so-called victory rings hollow, as it is only one step along a potentially long road towards achieving any substantive gains. It is one thing for the court to make a finding that Métis and non-status Indians are included within the scope of section 91(24). It is another thing for the federal government to act on that finding. Within the context of the division of powers, possessing the jurisdiction to act does not generally compel the federal government to act. ${ }^{6}$

The long term goal of the plaintiffs is, no doubt, to eventually achieve a ruling or policy change which would result in the inclusion of Métis and non-status Indians within the scope of beneficiaries entitled to various programs that only status Indians under the Indian Act are currently entitled to, such as post-secondary funding and non-insured health benefits. Thus, there is still a long way to go to achieving any real benefit. Equality claims are likely necessary to persuade the federal government to act, and it is far from certain whether they will be successful given the current jurisprudence that recognizes the validity of legal distinctions between disadvantaged groups, even ones similarly situated culturally and socially. ${ }^{7}$ The financial implications of inclusion on the federal purse will likely result in strong resistance by the current federal government to further such equality-based claims.

Despite being perceived as a victory, the decision is ultimately very destructive of the well-being of Métis peoples, indeed all Indigenous peoples, living in Canada. The plaintiffs seem to have conceded that section $91(24)$ is a broad plenary power which gives the authority to the federal government to unilaterally legislate over those included within its scope. In doing so, the plaintiffs admit to the fact that it is justifiable for the federal government to unilaterally rule over otherwise independent self-determining peoples and to legislatively "control” the nations Indigenous to North America in a hierarchical and inherently colonial relationship. In a sense, this treats collective independent peoples no differently than legislating with respect to the subject matter of "shipping" or the "postal service.” This effectively diminishes peoples and nations to simply "subject matter.” Such asymmetrical jurisdiction thereby eliminates any independent legal or political agency of the target "subject matter." As Aboriginal peoples captured by section 91(24), we become objects instead of contributing equal partners in confederation. We become encased in a

In a report for the National Aboriginal Health Organization entitled Maskikiwenow: The Métis Right to Health Under the Constitution of Canada and Under Selected International Human Rights Obligations (Ottawa: NAHO, 2009), online: National Aboriginal Health Organization <http://www.naho.ca/ documents/metiscentre/english/2011_right_to_health.pdf>, I document the Métis health deficit and how this deficit is exacerbated by Métis individuals often being unable to access health services because of jurisdictional squabbles between provincial and federal authorities.

$6 \quad$ See Peter W Hogg, Constitutional Law of Canada (Toronto: Carswell, 2012) at 12-1 and following. There are some limited cases where the Constitution requires governments to act, particularly in the context of denominational education and language rights. See for example Doucet-Boudreau v Nova Scotia (Minister of Education), 2003 SCC 62, [2003] 3 SCR 3, where the appellant's rights to minority official language education under the Constitution allowed the court to issue an injunction to proactively require the province of Nova Scotia to build a school. The exception to the general rule may arguably apply in the case of furthering the interests of Indigenous peoples or their unique human rights currently under debate in judicial and academic literature.

7 See e.g. Lovelace v Ontario, 2000 SCC 37, [2000] 1 SCR 950; Alberta (Aboriginal Affairs and Northern Development) v Cunningham, 2011 SCC 37, [2011] 2 SCR 670. 
virtual prison with no independent freedom but for that which the federal government graciously allows. ${ }^{8}$

Admittedly, this is painting a rather harsh picture of the implications of Daniels and much of what was said above needs to be put into the broader expanded context of sections 35 and 25 of the Constitution. It is not completely accurate to say that the federal government, through the operation of section 91(24), has virtually unchecked absolute power. Such power must now, since 1982, be balanced against proven Aboriginal and Treaty rights, protected in section 35, from unjustified unilateral interference by federal or provincial authorities. Nevertheless, the main point remains substantially accurate for a number of reasons. First, it is notoriously difficult for Aboriginal peoples to secure proven Aboriginal and Treaty rights as all claims are contested by federal or provincial governments, and the litigation costs are enormous. ${ }^{9}$ Second, even if an Aboriginal plaintiff (or, in most cases, a defendant) party is successful in getting an Aboriginal rights based claim funded, the test applied by the courts for proving an Aboriginal right is exceedingly narrow and excessively onerous. ${ }^{10}$ Moreover, once proven, the courts may characterize the interference as not substantial enough to violate the Constitution or decide that government interference with the proven right is justified under a generously framed Oakes-like section 1 analysis. ${ }^{11}$ Thus, the section 35 counter-check on government legislative power remains largely an illusion.

The definition adopted by the Federal Court in Daniels conceptualizes section 91(24) as plenary in nature (that is, a complete and unlimited vesting of power and control to legislate over the subject matter). However, this conceptual approach to section 91(24), seemingly unquestioned by the Court and not contested by the plaintiffs or the federal government, is an incorrect understanding of the nature of the power provided for in section 91(24). It has taken many years for the case to be decided on its merits. In the meantime, the law has evolved, but the parties' positions have not. Since 2001, the United Nations has endorsed the Declaration on the Rights of Indigenous Peoples which regards unilateral decision-making by states that impacts Indigenous peoples' interests as a violation of fundamental human rights. ${ }^{12}$ Moreover, the doctrine of the Honour of the Crown has emerged in the jurisprudence

These days virtually no bill that touches on Aboriginal issues can be passed by Parliament without being the subject of criticism by First Nations concerned that such unilateral action without consultation violates the equal nation to nation relationship on which the Treaties are said to be based. Although not an Aboriginal rights case, the Daniels case is characteristic of the practical difficulties facing Aboriginal plaintiffs bringing claims forward. It cost the Congress of Aboriginal Peoples over $\$ 2$ million and the federal government fought against the case every step of the way. Justice Phelan expressly noted in Daniels that the federal government made numerous efforts to curtail this litigation (supra note 1 at para 42).

10 In $R v$ Van der Peet, [1996] 2 SCR 507, the Supreme Court of Canada imposed a test that required an Aboriginal claimant to prove for each and every specific claim that the right was a specific activity, custom, or practice distinctive to the culture of the Aboriginal group prior to European contact and was not the product of European influence. The evidential burden that this test imposes is often sufficient to defeat a claim before it can be pronounced on its merits.

11 Ibid.

12 United Nations Declaration on the Rights of Indigenous Peoples, GA Res 61/295, UNGAOR 61st Sess, UN Doc 419, (2007) [United Nations Declaration]. See in particular Articles 8 and 18. Relevant parts of the Preamble state:

Recognizing also the urgent need to respect and promote the rights of indigenous peoples affirmed in treaties, agreements and other constructive arrangements with States.... Considering also that treaties, agreements and other constructive arrangements, and the relationship they represent, are the basis for a strengthened partnership between indigenous peoples and the States

Encouraging States to comply with and effectively implement all their obligations as they apply 
as an overarching fundamental principle for assessing the veracity and integrity of the Crown. Aboriginal relations, especially the duty to consult aspect of the doctrine, has much to say about the obligations of government before it enacts law or policy that affects asserted Indigenous interests. ${ }^{13}$

The assumption of plenary power is incorrect for two main reasons. Firstly, the idea that one people (or society) has the right to unilaterally legislate over another separate people is in contravention of the doctrine of self-determination. This is unacceptable in an age of respect for human rights. Thus, an interpretation that abides by contemporary human rights would necessarily require the courts to invoke the principle of the living tree and interpret the provision in accordance with contemporary standards of peoplehood equality. This would be consistent with the objective of section 35 to reconcile the relationship between Aboriginal peoples and the settler state. Justice Phelan makes note of the race-based nature of section 91(24) and asserts that care should be taken to ensure that stereotypes are not reinforced by its interpretation. However, he fails to appreciate that the provision is, without imposing a check on its unilateral reliance by federal authority, inherently racist as it offends fundamental human rights. ${ }^{14}$

Second, the characterization given by Justice Phelan of the purpose behind section 91(24) arguably correctly identifies three primary objectives for including section 91(24) in the Constitution and for allocating authority to the federal government. However, it fails to reconcile the internal inconsistency between the objectives. The Court neglected to consider the relative weight of each of the identified objectives and their relationships to one another. This resulted in the failure of the Court to recognize that the plenary power of section 91(24) is not absolute, but rather conditional in nature. Both points will be elaborated upon further below, but first it is appropriate for the benefit of the discussion that follows to set out what the court identified as the objectives and purpose of section 91(24).

The Federal Court held that the purposes of section 91(24) are:

- To control native peoples where necessary to facilitate development of the Dominion;

- To honour Crown obligations inherited from Britain and to extinguish interests that stood in the way of confederation; and

- To civilize and assimilate native peoples. ${ }^{15}$

Justice Phelan held that it is consistent with these purposes to give a broad and liberal interpretation to section 91(24) to capture within its scope "people who are defined, at least in a significant way, by their native heredity,” which would include non-status and Métis

to indigenous peoples under international instruments, in particular those related to human rights, in consultation and cooperation with the peoples concerned. 
people. ${ }^{16}$ Justice Phelan's conclusion on the scope of section 91(24) is a valid interpretation, but Justice Phelan failed to appreciate that the nature of the power must accord with present day principles representative of a decolonizing Canada.

\section{A HuMAN Rights INFORMEd DEFINITION OF SECTION 91(24)}

The proper interpretation of section 91(24) in a contemporary context should be limited to that of being a "treaty power" to negotiate with nations and peoples who occupy and possess territory that Canadian authority wished to acquire. It matters not the ethnic composition of such communities. These are political communities possessing a prior claim to the territory. This understanding of Aboriginal peoples as political societies is consistent with a treaty power interpretation to section 91(24). Moreover, this constitutionally assigned federal power to negotiate would also serve the objectives of section 91(24) as identified by Justice Phelan, although such objectives would now need to be achieved incrementally, initially through consensual agreements (treaties) between the federal and Aboriginal governing authorities, and then by relying on section 91(24) to implement those agreements under the efficiencies of a central government of the Canadian federation. The power under section 91(24) would properly include the power to implement the terms of such consensual treaties which may, to a greater or lesser degree, match the other two objectives of facilitating the development of the Dominion and the civilization of "Indians." Naturally, the objective of "civilization" is no longer acceptable in a society that realizes that Indigenous societies were far from uncivilized and that various accounts that held otherwise are tainted with uninformed racist and stereotypical imagery. ${ }^{17}$

Based on the living tree doctrine of constitutional interpretation and the broad and generous progressive approach recently adopted by the Supreme Court of Canada, this is how section 91(24) should be defined today — if it is to be consistent with contemporary human rights values and principles. To acknowledge that the federal government has power to legislate unilaterally "over” Aboriginal peoples is colonial thinking of a bygone era. The failure of the plaintiffs to challenge this colonial understanding of section 91(24) in the context of Daniels is ironic because it essentially admits that it was the intention of the framers of section 91(24) to colonize and assimilate Métis and non-status people - and extinguish their title to their lands - to the same extent that they hoped to colonize and assimilate status Indians and extinguish Indian title.

Given the possible emergence of a paradigm shift from a colonial-based understanding of Aboriginal-Canadian relations to a human rights-based understanding section 91(24) must, to be consistent with minimum state human rights obligations, be confined to a power to negotiate and implement change by consent through Treaty (interpreted broadly as including any agreement regardless of how complex or simple the agreement may be as long as it is

Ibid at para 544 .

For a thorough account of the history of contact and how a dehumanized account of Indigenous peoples influenced legal thinking from the beginning of contact see Robert Williams Jr, The American Indian in Western Legal Thought: The Discourses of Conquest (New York: Oxford University Press, 1990). In the Canadian context see Royal Commission on Aboriginal Peoples, Report of the Royal Commission on Aboriginal Peoples: Looking Forward, Looking Back, vol 1 (Ottawa: Canada Communication Group, 1996). 
between Aboriginal and Canadian authorities) ${ }^{18}$ It is contrary to human rights principles and the aspirations of Aboriginal peoples to argue for an interpretation of section 91(24) that reinforces a colonial relationship. Any interpretation that gives Canada the ability to unilaterally enact laws that affect the interests of Indigenous peoples and the corresponding right to consent to policy or legislative initiatives that may affect the interests of Indigenous peoples (be it related to resources, culture, or institutions), is a serious step backwards.

It is somewhat ironic that the plaintiffs are trying to become "Indians" during a time when many "Indians" are trying to get out from under the colonial legacy of federal oppression as manifested in the Indian Act. This desire to try to get out from under the Indian Act and section 91(24) exists so that the relationship may be transformed once again into a true nation-to-nation relationship as was the case during the early period of mutual recognition by local colonial officials. Yet, here we find the plaintiffs are actually trying to get into this acknowledged oppressive legislative regime.

This approach of lumping all Indigenous nations into one category of "Indians" is also problematic because such a definition forces a unification of distinct societies and essentializes multiple nations and cultures into one uniform and artificial ethnic class. Indigenous peoples are as unique and different from each other as they are from the English and French. Moreover, this essentializing feature of a singular definition inappropriately influences government policy makers and causes them to design programs and services that apply equally to all "Indians" regardless of the many and varied nations, cultures, institutions and aspirations they possess. One policy does not, and will not, fit all. The Daniels decision does not contest the racialization of the discrete and multiple Indigenous identities into a singular essentializing definition. Indeed, the case dangerously reinforces such racialization and thereby contributes to the ongoing erasure of the political status of the various Indigenous peoples which is the inevitable by-product of conceptualizing the distinct peoples of the nations Indigenous as a singular collective of "aboriginals," "natives," or "Indians" (that is, as one race).

The court has an obligation, where feasible and consistent with the purpose of the constitutional provision, to interpret the provision in a manner consistent with human rights obligations and in step with prevailing contemporary values. The Court, and the parties to the litigation, failed (by not even addressing the issue) to articulate a post-colonial definition of section 91(24).

The above discussion has assumed, for the purpose of discussion, that the intent of the framers of section 91(24) was to provide a broad unconditional plenary power over "Indians." I have argued that a proper contemporary interpretation would allow for the definition to evolve in a manner consistent with human rights. In other words, regardless of how section 91(24) was defined in 1867, today the definition must evolve so that it keeps pace with a decolonizing Crown-Aboriginal relationship. However, as will be argued below, this assumption is not historically accurate if one more judiciously appreciates the relationship between the listed objectives identified by Justice Phelan as the purposes behind section 91(24). Thus, section 91(24), from its beginning, was a limited power to ensure 
compliance with Crown obligations which was based on consensual relations reflected in and required by the Royal Proclamation of $1763 .^{19}$ This historical perspective of deference to negotiations is evident in the extensive treaty negotiations record described by Arthur Ray, Jim Miller, and Frank Tough in their comprehensive book on prairie treaties. ${ }^{20}$ For example, they state that "White settlement of Indian lands without Indian consent was inconsistent with the Royal Proclamation of 1763 and the commitments that the dominion had made during the transfer of Rupertsland." ${ }^{21}$ Importantly, they note that "civilization” defined historically as the pursuit of agriculture (instead of hunting and trapping), was not to be presumed or forced upon the parties to a treaty, although encouraged. ${ }^{22}$ Note that these treaty negotiations (with the understanding of deference to Indian consent) took place in the early 1870s, rather contemporaneously with the enactment of section 91(24) in 1867.

\section{Not All OBJECTIVES ARE EQUAL}

The objective of section 91(24), including the obligation of upholding the honour of the Crown, does not possess the same relative weight as the objectives of assimilation and civilization of the Indians. ${ }^{23}$ In order to be meaningful, the honour of the Crown principle must be given greater weight and priority over the other two objectives. As the Supreme Court of Canada recently stated in Beckman and Manitoba Métis Federation, the principle of the honour of the Crown transcends Aboriginal and Treaty rights and is an overarching general principle for guiding Aboriginal-Crown relations. ${ }^{24}$ An interpretation consistent with human rights would regard the assimilation and control of Indians as objectives that are secondary to, and dependent on, the primary objective of the honour of the Crown. Instead of a list of three equal objectives, the formulation of section 91(24)'s objectives should have been organized and framed as follows:

- $\quad$ To honour Crown obligations inherited from Britain;

- $\quad$ And to extinguish interests that stood in the way of confederation;

- $\quad$ To control native peoples where necessary to facilitate development of the Dominion; and

- $\quad$ To civilize and assimilate native peoples.

An interpretation of section 91(24) that gives precedence to upholding the honour of the Crown is consistent with the Royal Proclamation of 1763 and the view that European

Chippewas of Sarnia Band v Canada (AG) (2000), 51 OR (3d) 641 (OCA) [Chippewas of Sarnia]. In this case, the Ontario Court of Appeal, although speaking to the issue of Aboriginal title, stated "[T] Crown continued to recognize Indian rights in their land, continued to require that those rights be surrendered only to the Crown on consent, and continued to regard those rights as communal and surrenderable by a public manifestation of the First Nations consent to surrender" (at para 198). Arthur Ray, Jim Miller \& Frank Tough, Bounty and Benevolence: A History of Saskatchewan Treaties (Montreal: McGill-Queen's University Press, 2000). After all, if the power of section 91(24) was unconstrained, why the necessity of entering into consensual treaty agreements in the first place?

Ibid at 68 .

Ibid at 67 .

Ibid at 67-75.

Beckman, supra note 13; Manitoba Métis Federation, supra note 13. 
settlement could not proceed without consensual surrender of pre-existing Indigenous interests. ${ }^{25}$ The objectives of extinguishment, control, and civilization would be read as dependent on satisfying the primary objective of upholding the honour of the Crown through consensual treaty making. The evidence reviewed by the Court in Daniels is equally consistent with this interpretation. However, given federal legislative history to date, one would have to conclude that the federal government failed to abide by this alternative formulation consistently over many years, which seems implausible. In essence, one would have to conclude that the federal Crown failed to appreciate the relevant distinctions between the objectives and the primacy of upholding the honour of the Crown and thus enacted legislation over the years mistakenly thinking it had unconditional plenary power (or perhaps knowingly disregarding the distinction), taking the view that all objectives were of equal weight when in fact they were not. Admittedly, this is a stretch. Yet, the implausible becomes plausible when this interpretation is combined with the importance of a contemporary postcolonial interpretation of the provision relying on the living tree metaphor of the Constitution as justification.

Furthermore, the differential formulation is logically preferable because an undifferential list of objectives is internally incoherent. How can the honour of the Crown to negotiate a mutually agreed upon relationship between Aboriginal parties and the Crown (which is the nature of the British obligation adopted by Canada in 1867), be reconciled with a unilateral plenary power to civilize and assimilate? Of course, one could argue that the honour of the Crown in 1867 could be upheld by unilateral federal action under a paternalistic conceptualization of Indigenous competence. Again, however, such a view of Indigenous capacity and lack of independent agency, while perhaps valid in 1867, would have the taint of assimilation today and has no valid play in a contemporary Canadian society where the relationship is grounded in a human rights equality perspective necessitating that the provision's interpretation be adjusted in a way consistent with contemporary values.

The first objective of upholding the honour of the Crown must logically proceed the others. This approach allows for all objectives to be reconciled if we view the provision as allowing the federal government the plenary power to implement the outcome of treaty negotiations regardless of whether the sphere of provincial power is implicated.

A power that is broad in its application to various Indigenous peoples (so none are excluded), but non-existent as to its capacity to allow unilateral action, is the most appropriate interpretation of section 91(24). This does not necessarily mean that past legislation, such as the Indian Act, would automatically be found ultra vires. There are constitutional mechanisms and precedent that can be brought to bear if such legislation were to be challenged. It is beyond the scope of this comment to elaborate, but the concept of the rule of law as it was applied in the Manitoba Reference case may be one such mechanism. ${ }^{26}$ Moreover, there may be people of Aboriginal heritage that do not belong to an Aboriginal community or collective due to historical factors. The federal government could act on their behalf if they are unable to represent themselves collectively. There are some complex questions that would arise if the court were to adopt an interpretation of section 91(24) 
consistent with the views described above, but such uncertainties should not stop us from upholding the honour of the Crown within an internally consistent human rights-embracing constitution.

Reimagining federalism as a dialogical process that reconciles diversity with unity is consistent with the honour of the Crown. ${ }^{27}$ Sa'ke'j Henderson has described the impact of section 35 rights as "converging them with governmental power into a patriated constitutional order.... The post-colonial constitutional order and dialogical governance prevents inconsistent federal and provincial action toward Aboriginal peoples' rights." ${ }^{28}$ Selfgovernment is a right that is inherent to Aboriginal peoples. Although, as the Supreme Court of Canada has consistently reminded us, such rights have virtually been ignored in the past, ${ }^{29}$ they cannot be ignored any longer. To do so brings dishonour to the Crown. ${ }^{30}$ True selfgovernment, where Aboriginal peoples are recognized as equal partners in confederation, cannot be made subservient under section 91(24). It is difficult, if not impossible, to reconcile an absolute power to legislate over Aboriginal peoples in section 91(24) with a post-colonial equality-based understanding of Aboriginal collective authority in a united federal union. Section 91(24) must be understood in today’s context. It cannot be interpreted in isolation of Canada's constitutional evolution which now includes section 35.

The constitutional recognition of the honour of the Crown and fiduciary relationship reverses the colonial era's judicial precedent that the federal or provincial governments could unilaterally modify Aboriginal rights. $^{31}$

Section 91(24) must be read in a way that logically converges with section 35 rights, including collective governance rights. Whether the Indian power is understood as always having been limited to consensual authority as argued above, or that it has evolved that way, ultimately matters little. What matters is the kind of Canada we are entitled to have.

\section{CONCLUSION}

The analysis offered above leads one to the inevitable conclusion that section 91(24) legislation can only apply to individuals through their communities to the extent that it is acceptable by such communities based on Treaty or other valid consensual arrangements and understandings. These are respectful relations. This is reconciliation. This limitation on federal government unilateral action in a decolonizing Canada should not be restricted to those Indigenous interests that are capable of meeting the onerous test of being integral to the distinctive culture of the Aboriginal community, but should be extended to all matters of relevant concern to Aboriginal communities and governments.

28 James Youngblood Henderson, First Nations Jurisprudence and Aboriginal Rights: Defining the Just Society (Saskatoon: Native Law Centre University of Saskatchewan, 2006) at 232 [Henderson, First Nations Jurisprudence].

$R \vee$ Sparrow, [1990] 1 SCR 1075.

Manitoba Métis Federation, supra note 13.

Henderson, First Nations Jurisprudence, supra note 28 at 235-36. 